\title{
Exploring the Boundary Conditions of Social Influence for Social Media Research
}

Dharshani Chandrasekara

Faculty of Information Technology

Monash University

Melbourne, Australia

Email: dharshani.chandrasekara@monash.edu

\section{Darshana Sedera}

Faculty of Information Technology

Monash University

Melbourne, Australia

Email: darshanasedera@gmail.com

\begin{abstract}
Along with the proliferation of social networking sites (SNS), people around the world have gained the ability to influence each other in terms of many aspects of lives may it be a political interest or a simple purchase decision. However, most of the SNS studies have employed social influence constructs that were established prior to the advent of SNS to understand the nature and impact of social influence. Even though the application of such theories for SNS has generated a wealth of knowledge, it is vital to acknowledge the necessity of a new perspective that is specific to the current context. Therefore, we conducted a review of 65 studies to explore which social influence constructs have been employed by previous SNS studies and introduced five boundary conditions that should be taken into consideration when employing social influence theory for future SNS studies.
\end{abstract}

Keywords Social influence, social impact, social media, boundary conditions, literature review 


\section{Introduction}

Along with the advent of SNS, people around the world were able to step into a new level of social interactions (Palekar et al. 2018). According to the latest statistics, in 2018, the global population using SNS reached 3.196 billion, with an annual increase of 13\% (Chaffey 2018). The proliferation of SNS like Facebook and Twitter also has been acknowledged in the academic literature for exerting influence on the individual and the society (Kane et al. 2014; Oh et al. 2017; Sedera et al. 2017; Sedera et al. 2016). Sinha and Fung (2018) argue that individuals can be treated as 'micro-influencers.' Such commentary further highlights the social influence and social impact ${ }^{1}$ generated by people through SNS. On the other hand, the magnitude of the social influence is also gaining traction in SNS. For example, it is estimated that the average Facebook user has 338 friends (Smith 2017), with another 15\% of users with more than 500 friends (Smith 2014). The average Twitter user has 707 followers (MacCarthy 2016). Such a large number of 'micro-influencers' are interacting on a daily basis on SNS platforms. The volume, voracity and influence of such high levels of influences can push even the established theoretical views on social influence into reconsidering their theoretical boundaries.

Even before the proliferation of SNS, there has been a continuous effort to understand the 'influence' of society on the individual (Kelman 1958). For the past several decades, studies have delivered various theories and frameworks to better understand social influence (Bagozzi and Dholakia 2002; Kelman 1958; Kuan et al. 2014; Latané 1981). With the advent and mass proliferation of SNS, researchers agree that social influence is growing and changing (Bagozzi and Dholakia 2002). Researchers of various disciplines have contributed through a wealth of studies to better understand the social influence that occur as a result of people's interactions in SNS, including information systems (Alarifi et al. 2015; Sedera et al. 2017), marketing (Dholakia et al. 2004; Sedera et al. 2017), organizational environment (Arvidsson and Holmström 2013) and political science (Tufekci and Wilson 2012). Moreover, the impact of SNS has been discussed in various sectors, including automobile (Wang et al. 2015), music (Dewan et al. 2017), and film industry (Oh et al. 2017).

The objective of this research paper is to explore the boundary conditions of these two theoretical foundations of social influence (Kelman 1958) and social impact (Latané 1981), especially in light of the novelty in SNS. Despite the continuing advancements of SNS, these boundary conditions have received very little attention. Without a clear understanding of the boundary conditions in this rapidly changing context, applying existing theoretical conditions could lead to incorrect interpretations (Busse et al. 2017). In an assessment of 65 studies on social influence published in top-tier journals, we found little evidence that such boundary conditions are established, reviewed, or revised. Herein, we propose five boundary conditions necessary for the utilization of the current theories of social influence. The paper proceeds in the following manner. First, it provides an overview of the two streams of social influence studies. Then it investigates the constructs employed in social influence using the literature sample. Next, five boundary conditions are presented and explained in light of the constructs employed in the social influence studies.

\section{Theoretical Foundations of Social Influence}

The SNS research on social influence is mainly based on two theoretical streams (i) social influence theory (Kelman 1958) and (ii) social impact theory (Latané 1981).

\subsection{Stream 1: Social Influence}

One of the key theories in social influence was introduced by Kelman (1958) through his research paper on "Compliance, identification, and internalization: Three processes of attitude change." According to this particular study (Kelman 1958), social influence can be accepted by three different types of constructs namely, compliance which is also identified as subjective norm, and refers to the influential capabilities of significant others or powerful people in the influencee's life (Bagozzi and Dholakia 2002), identification, which is the process where a person acts in a certain way to gain acceptance or a feeling of belongingness in a particular group or an individual (Kelman 1958) and internalization, through which, a person would engage in a particular behaviour because the behaviour is agreeable with his/her value system (Kelman 1958). However, based on Kelman's study, in general, social influence can be defined as the process of attitudinal or behavioural change that occurs within a person due to different types of communications a person engages in. The foundation for the social influence studies in

\footnotetext{
${ }^{1}$ The terms "social influence" and "social impact" have been used interchangeably (Latané 1996) due to the similarity of the effect they generate. Henceforth, these two will be referred to as "social influence' in general to avoid confusion.
} 
Information Systems, particularly on SNS, has been mainly laid with the support of this substantial contribution of Kelman. In fact, a number of studies exploring the social influence in virtual communities have utilized Kelman's theory on social influence as the basis for their research (Bagozzi and Dholakia 2002; Bagozzi et al. 2007; Dholakia et al. 2004; Zhou 2011). However, the social influence research in virtual communities has not been limited to the study of these three processes in the key theory of social influence by Kelman. Kuan et al. (2014) utilize informational social influence and normative social influence to understand how purchase decisions in group buying sites can be affected by social influence. Under this study, informational influence has been applied for situations where people would make decisions based on others actions and judgments thus treating them as sources of information, and normative influence is applied when people take decisions to comply with others, based on others preferences or expectations. Further, Kuan et al. (2014) indicate that both informational and normative influences are contributing to conformity. In addition, another different perspective of social influence studied under SNS is the concept of peer influence. Peer influence can be defined as the process in which peers or friends play an important role when a particular person is making a decision to act in a particular way (Godinho de Matos et al. 2014).

In social psychology, together with some of the above-mentioned aspects of social influence, many other factors have also been incorporated in comprehending social influence (Vaughan and Hogg 2005). Vaughan and Hogg (2005) have further highlighted obedience, persuasion, conformity, normative influence, informational influence, majority influence and minority influence as different processes of social influence through which a person can be directed to act in a certain way. If social influence of SNS is considered in a broader perspective, the researchers in the Information Systems domain have also utilized the Spiral of Silence to explain how people are influenced in the digital spheres to remain as mere passive recipients due to social and organizational factors (Palekar et al. 2018). Thus, it is evident that research in SNS has covered a broad spectrum of theories and concepts related to social influence when understanding the user behaviours in the digital sphere. Overall, social influence studies in information systems employ constructs like, compliance, identification, internalization, peer influence, informational influence and normative influence as the key variables (Bagozzi and Dholakia 2002; Kuan et al. 2014; Sedera et al. 2017; Zhang et al. 2018).

\subsection{Stream 2: Social Impact}

The theory of social impact was first introduced by Latané in 1981. Latané (1981, p. 343) defines social impact as "the great variety of changes in physiological states and subjective feelings, motives and emotions, cognitions and beliefs, values and behaviour, that occur in an individual, human or animal, as a result of the real, implied, or imagined presence or actions of other individuals". In order to have an impact on an individual, he further comes up with three constructs that should be present, namely, strength - "the salience, power, importance, or intensity of a given source to the target", immediacy "closeness in space or time and absence of intervening barriers or filters" and number - "how many people there are" (Latané 1981, p. 344).

Even though social impact theory was established prior to the advent of SNS, several studies have utilized the theory in explaining the behaviour of individuals in digital spaces (Kwahk and Ge 2012; Miller and Brunner 2008). As a matter of fact, when relating the construct of immediacy which is mainly regarding the physical proximity between the source and the target of impact, a study has defined immediacy in the digital environment in terms of "participant's proximity to the chat room dialogue as evidenced by a participant's number of contributions and their total number of contributed words" (Miller and Brunner 2008, p. 2977). With regard to the construct namely, strength, the same study has used interpersonal factors such as assertiveness and exaggeration as indicators of strength in the person who is making an influence online. Overall, we identify three key constructs that generate social impact, namely, the strength of the network, immediacy, and the number of sources (Latané 1981). It was also noted that some studies of social impact, commonly employ two concepts of the social influence theory of Kelman (1958) namely, normative influence and informational social influence (e.g. Kwahk and Ge 2012). On the other hand, the information and the knowledge to which that person would be exposed in SNS would make him/her affected by informational influence. The study has further recognized that SNS lead to a high level of informational influence because of which the SNS users' online activities such as visiting e-commerce platforms and purchasing items online would be influenced (Kwahk and $\mathrm{Ge}$ 2012).

\section{The Overview of the Literature Sample}

The objective of the literature analyses was (i) to develop an understanding of the utility of the two streams of studies, (ii) to identify the constructs of social influence and (iii) propose boundary conditions 
necessary. Conducting a literature analysis was decided as the most appropriate for the study since the authors identified that even though theories of social influence have been widely utilized in the domain of information systems, (Bagozzi and Dholakia 2002; Kuan et al. 2014; Sedera et al. 2017; Vannoy and Palvia 2010), up to date, a comprehensive literature analysis on this topic has not been conducted. In the meantime, a literature analysis would lay a strong foundation to facilitate future research that would employ social influence constructs to examine social interactions in SNS. The literature sample includes an amalgamation of: (i) basket-of-8 journal papers in the information systems published between 2008 to $2018^{2}$, (ii) most cited studies on the theories of social influence, and (iii) PlumX3 highly cited social media research that is not in segment i or ii. We used keywords namely "social influence", "influence", "social influence and social media", social influence and social networks", "social media", "social impact", "social impact and social media", "impact", and "social interaction and social media" in the process of identifying the most suitable literature for the sample. First, the seminal papers on social influence and social impact theory were added to the literature sample. Then from the basket-of- 8 journals, research papers on social influence and virtual communities were selected based on the keywords. Finally, based on the reference lists of the selected journal papers, which matched our search criteria, snowballing method was followed to identify research papers that are of similar nature. The search resulted in a total of 65 research publications that were suitable for the analysis to address the objectives of the study, representing information systems, management, marketing, political science, and psychology disciplines. The complete sample is available in Table $1^{4}$.

\subsection{Analysis}

Once the literature sample of the 65 studies was assembled, two co-authors distilled the constructs of measurement. Table 1 includes the study and the corresponding construct employed; denoted through columns ' $\mathrm{A}$ ' to ' $\mathrm{I}$ '. The constructs of social influence included: (A) compliance, (B) identification, (C) internalization, (D) peer influence, (E) informational influence, and (F) normative influence. Social impact stream of research included: (G) immediacy, (H) strength, and the (I) number of sources. The mapping of the constructs was completed by one researcher and then were verified by another. Comparison of the individual classifications revealed an average inter-coder reliability exceeding $80 \% 5$.

According to the analysed data, the three constructs that were discussed the most in the selected literature were normative influence, compliance, and identification respectively. From the constructs under social impact, strength and the number of sources were the two constructs that were discussed the most. The least discussed constructs of social influence were informational influence and peer influence. Under social impact, immediacy was the least discussed construct.

The analysis highlighted that there is a possible (and perhaps unintentional) overlap between the constructs of social influence and social impact. For instance, Latané (1981, p. 344), defines strength in social impact as "the salience, power, importance, or intensity of a given source to the target." Kelman (1958) on the other hand, refers to compliance as a process due to which an individual would behave in a particular way in order to receive rewards or approval from a person or a group, or due to the fear of being rejected. Further, he refers to identification as a process due to which a person would be influenced either to generate or to continue a successful relationship with another person or a group. Kelman (1958), further adds that for these two processes to be successful, the determinants of influence, namely "the relative importance of the anticipated effect" and "the relative power of the influencing agent" should be considered. While strength in social impact research has been discussed in the perspective of the source of impact, compliance and identification have been discussed in the perspective of the target. However, the power, salience, intensity, and the importance can be considered as attributes that should be possessed by the influencer under compliance and identification to influence the actions of the target. Such overlaps may influence the boundary conditions discussed later in this paper.

Moreover, we observed an overlap between social influence and impact studies. It was observed that $\sim 23 \%$ of the literature sample (15 studies) has employed both theoretical streams of social influence and social impact. In other words, in a study of social influence, constructs of social impact are either

\footnotetext{
${ }^{2}$ The reason for selecting the time range from 2008 to 2018 is to obtain the most up to date research findings relevant for the objectives of the research. Once the most relevant research papers were selected, the authors then used snowballing method to identify other relevant research publications from the reference lists of the selected research papers.

3 PlumX metrics "gathers and brings together appropriate research metrics for all types of scholarly research output" (PlumX Metrics - Plum Analytics" n.d.)

4 The reference list of the literature review table can be obtained by visiting the following link: https://docs.google.com/document/d/1kulVbe2-GdhRTKAsB69WIxfr5WWHUg8TESgk e3WmeQ/edit?usp=sharing

5 Krippendorff (1980) recommends inter-coder reliability of at least $70 \%$
} 
implicitly discussed or measured for analysis purposes. In a similar manner, some social impact studies consider the influence of the network post-hoc.

The literature sample in Table 1 is chronologically ordered. While it was expected that the number of studies employing social influence and impact would increase over time (with the advent and proliferation of SNS), in reality, the number of studies is plateauing. Moreover, studies introduced no new constructs for social impact. However, several new constructs were introduced in studies of social influence to capture the social influence generated by people in SNS.

The context of social influence is an important consideration that would affect the study outcomes. For example, the social influence theory was originated in the face-to-face, physical context of human interactions. However, we observed that the theory has been employed by approximately $65 \%$ studies that have considered social media or virtual community as the context (denoted with an $\left(^{*}\right)$ for virtual community studies and $\left({ }^{* *}\right)$ for social media studies in Table 1 ). Contrasting with the studies employing other media of social interaction, no study in our sample has specifically observed the theoretical challenges in employing the social influence in SNS.

\subsubsection{Focus on boundary conditions}

The literature sample demonstrates that, while we have made substantial leaps in technology by creating social networking sites arriving at a hyper-connected society, our theoretical foundations employed in information systems studies barely have changed. In particular, no study in our literature sample provides attention to possible boundary conditions when moving a theoretical foundation that was derived on the basis of face-to-face human influence to a context of augmented, inflated and excessive social influence of SNS. Yet, regardless of the context, all studies employ the same constructs (i.e. A to I in Table 1) without any justification. While the consistency in employing the constructs of social influence would lead to a cumulative tradition of research, this lack of acknowledgement of a major shift in the context (e.g. face-to-face to virtual being one of them) not only weakens our observations, it precludes us from making a precise understanding of the nature of social influence in the new context.

\section{Revisiting the Boundary Conditions}

Even though researchers from various disciplines have studied the nature of social influence generated in SNS on an individual (or society), much of the theoretical work underpinning these discussions have placed their foundations on the theories that were developed prior to the advent of SNS. Herein we specifically propose that, when considering social influence, studies must specify and observe conditions that the constructs are bounded by Dubin (1969). The boundary conditions are derived through a comparison of the conditions upon which the traditional social interactions (e.g. face-to-face) against the conditions upon which the digital interaction happens. These 'limiting values' are particularly potent in the SNS context. Lack of boundary condition specificity in emerging research could lead to either type-I or type-II errors. For example, you may reject the true null hypothesis (type-I) or fail to reject a false null hypothesis (type-II), by inadvertently selecting a particular sample that may not be 'random.'

In order to better illustrate, we identified five (5) salient bounding conditions that would affect the nature of social influence in the SNS era. These five factors can provide what Dubin called the 'boundaries' of the theory. Dubin (1969), states that "in order that a model may represent an empirical system, it has to have the boundaries corresponding to the empirical system. The boundaries are important to the specification of any theoretical model."

The 5 boundaries were recognized that would add meaning to the future SNS social influence studies: (i) the choice, (ii) space and proximity, (iii) the locus of social influence, (iv) the number of people and times, (v) the diversity and the variety of social influence. Exploring social influence using these boundary conditions would allow researchers to provide more profound insights into this emerging and important phenomenon of social media. Panels in Figure 1 provide a graphical illustration of the five boundary conditions specified for the social influence studies. 
Table 1. Literature Analysis ${ }^{6}$

\begin{tabular}{|c|c|c|c|c|c|c|c|c|c|c|c|c|c|c|c|c|c|c|c|}
\hline Study & A & $\mathbf{B}$ & $\mathrm{C}$ & D & $\mathbf{E}$ & $\mathbf{F}$ & $\mathbf{G}$ & $\mathbf{H}$ & $\mathbf{I}$ & Study & $\mathbf{A}$ & $\mathbf{B}$ & $\mathrm{C}$ & $\mathbf{D}$ & $\mathbf{E}$ & $\mathbf{F}$ & $\boldsymbol{G I}$ & $\mathbf{H}$ & $\mathbf{I}$ \\
\hline (Kelman 1958) & $\mathrm{Y}$ & $\mathrm{Y}$ & $\mathrm{Y}$ & $\mathrm{N}$ & $\mathrm{Y}$ & $\mathrm{Y}$ & $\mathrm{N}$ & $\mathrm{Y}$ & $\mathrm{N}$ & $* *$ (Zhou 2011) & $\mathrm{Y}$ & $\mathrm{Y}$ & $\mathrm{Y}$ & $\mathrm{N}$ & $\mathrm{N}$ & $\mathrm{Y}$ & $\mathrm{N}$ & $\mathrm{Y}$ & $\mathrm{N}$ \\
\hline (Latané 1981) & $\mathrm{Y}$ & $\mathrm{N}$ & $\mathrm{N}$ & $\mathrm{N}$ & $\mathrm{N}$ & $\mathrm{Y}$ & $\mathrm{Y}$ & $\mathrm{Y}$ & $\mathrm{Y}$ & (Datta 2011) & $\mathrm{Y}$ & $\mathrm{Y}$ & $\mathrm{Y}$ & $\mathrm{N}$ & $\mathrm{N}$ & $\mathrm{Y}$ & $\mathrm{N}$ & $\mathrm{Y}$ & $\mathrm{N}$ \\
\hline (Nowak et al. 1990) & $\mathrm{Y}$ & $\mathrm{N}$ & $\mathrm{N}$ & $\mathrm{N}$ & $\mathrm{Y}$ & $\mathrm{Y}$ & $\mathrm{Y}$ & $\mathrm{Y}$ & $\mathrm{Y}$ & (Shen et al. 2011) & $\mathrm{Y}$ & $\mathrm{Y}$ & $\mathrm{Y}$ & $\mathrm{N}$ & $\mathrm{N}$ & $\mathrm{Y}$ & $\mathrm{N}$ & $\mathrm{Y}$ & $\mathrm{N}$ \\
\hline (Latané et al. 1995) & $\mathrm{Y}$ & $\mathrm{N}$ & $\mathrm{N}$ & $\mathrm{N}$ & $\mathrm{N}$ & $\mathrm{Y}$ & $\mathrm{Y}$ & $\mathrm{Y}$ & $\mathrm{Y}$ & ${ }^{* *}($ Cheung et al. 2011) & $\mathrm{Y}$ & $\mathrm{Y}$ & $\mathrm{Y}$ & $\mathrm{N}$ & $\mathrm{Y}$ & $\mathrm{Y}$ & $\mathrm{N}$ & $\mathrm{Y}$ & $\mathrm{N}$ \\
\hline (Latané 1996) & $\mathrm{Y}$ & $\mathrm{Y}$ & $\mathrm{N}$ & $\mathrm{N}$ & $\mathrm{N}$ & $\mathrm{Y}$ & $\mathrm{Y}$ & $\mathrm{Y}$ & $\mathrm{Y}$ & $* *$ (Kietzmann et al. 2011) & $\mathrm{N}$ & $\mathrm{N}$ & $\mathrm{N}$ & $\mathrm{Y}$ & $\mathrm{N}$ & $\mathrm{N}$ & $\mathrm{N}$ & $\mathrm{Y}$ & $\mathrm{Y}$ \\
\hline *(Latané and Bourgeois 1996) & $\mathrm{N}$ & $\mathrm{N}$ & $\mathrm{N}$ & $\mathrm{N}$ & $\mathrm{N}$ & $\mathrm{N}$ & $\mathrm{Y}$ & $\mathrm{Y}$ & $\mathrm{Y}$ & $* *$ (Hanna et al. 2011) & $\mathrm{N}$ & $\mathrm{N}$ & $\mathrm{N}$ & $\mathrm{Y}$ & $\mathrm{Y}$ & $\mathrm{N}$ & $\mathrm{N}$ & $\mathrm{N}$ & $\mathrm{N}$ \\
\hline (Venkatesh and Davis 2000) & $\mathrm{Y}$ & $\mathrm{Y}$ & $\mathrm{Y}$ & $\mathrm{N}$ & $\mathrm{Y}$ & $\mathrm{Y}$ & $\mathrm{N}$ & $\mathrm{Y}$ & $\mathrm{N}$ & **(Fischer and Reuber 2011) & $\mathrm{N}$ & $\mathrm{N}$ & $\mathrm{N}$ & $\mathrm{N}$ & $\mathrm{N}$ & $\mathrm{Y}$ & $\mathrm{N}$ & $\mathrm{N}$ & $\mathrm{N}$ \\
\hline *(Bagozzi and Dholakia 2002) & $\mathrm{Y}$ & $\mathrm{Y}$ & $\mathrm{Y}$ & $\mathrm{N}$ & $\mathrm{Y}$ & $\mathrm{Y}$ & $\mathrm{N}$ & $\mathrm{N}$ & $\mathrm{Y}$ & **(Mir and Zaheer 2012) & $\mathrm{N}$ & $\mathrm{N}$ & $\mathrm{N}$ & $\mathrm{N}$ & $\mathrm{Y}$ & $\mathrm{N}$ & $\mathrm{Y}$ & $\mathrm{Y}$ & $\mathrm{Y}$ \\
\hline (Dholakia and Talukdar 2004) & $\mathrm{Y}$ & $\mathrm{N}$ & $\mathrm{N}$ & $\mathrm{N}$ & $\mathrm{Y}$ & $\mathrm{Y}$ & $\mathrm{N}$ & $\mathrm{Y}$ & $\mathrm{N}$ & $* *($ Kwahk and Ge 2012) & $\mathrm{Y}$ & $\mathrm{Y}$ & $\mathrm{N}$ & $\mathrm{N}$ & $\mathrm{Y}$ & $\mathrm{Y}$ & $\mathrm{Y}$ & $\mathrm{Y}$ & $\mathrm{Y}$ \\
\hline *(Dholakia et al. 2004) & $\mathrm{Y}$ & $\mathrm{Y}$ & $\mathrm{Y}$ & $\mathrm{N}$ & $\mathrm{Y}$ & $\mathrm{Y}$ & $\mathrm{N}$ & $\mathrm{N}$ & $\mathrm{N}$ & **(Tufekci and Wilson 2012) & $\mathrm{N}$ & $\mathrm{N}$ & $\mathrm{N}$ & $\mathrm{N}$ & $\mathrm{Y}$ & $\mathrm{N}$ & $\mathrm{N}$ & $\mathrm{Y}$ & $\mathrm{N}$ \\
\hline (Algesheimer et al. 2005) & $\mathrm{Y}$ & $\mathrm{Y}$ & $\mathrm{N}$ & $\mathrm{N}$ & $\mathrm{Y}$ & $\mathrm{Y}$ & $\mathrm{N}$ & $\mathrm{Y}$ & $\mathrm{Y}$ & $* *($ Lipsman et al. 2012) & $\mathrm{N}$ & $\mathrm{N}$ & $\mathrm{N}$ & $\mathrm{Y}$ & $\mathrm{N}$ & $\mathrm{N}$ & $\mathrm{Y}$ & $\mathrm{N}$ & $\mathrm{Y}$ \\
\hline (Lu et al. 2005) & $\mathrm{Y}$ & $\mathrm{Y}$ & $\mathrm{Y}$ & $\mathrm{N}$ & $\mathrm{Y}$ & $\mathrm{Y}$ & $\mathrm{N}$ & $\mathrm{Y}$ & $\mathrm{N}$ & $* *$ (Gensler et al. 2013) & $\mathrm{N}$ & $\mathrm{N}$ & $\mathrm{N}$ & $\mathrm{Y}$ & $\mathrm{Y}$ & $\mathrm{N}$ & $\mathrm{N}$ & $\mathrm{Y}$ & $\mathrm{Y}$ \\
\hline (Gallivan et al. 2005) & $\mathrm{Y}$ & $\mathrm{N}$ & $\mathrm{Y}$ & $\mathrm{Y}$ & $\mathrm{Y}$ & $\mathrm{Y}$ & $\mathrm{N}$ & $\mathrm{Y}$ & $\mathrm{N}$ & (Singh and Phelps 2013) & $\mathrm{Y}$ & $\mathrm{N}$ & $\mathrm{N}$ & $\mathrm{Y}$ & $\mathrm{Y}$ & $\mathrm{Y}$ & $\mathrm{Y}$ & $\mathrm{Y}$ & $\mathrm{N}$ \\
\hline (Lee et al. 2006) & $\mathrm{Y}$ & $\mathrm{N}$ & $\mathrm{Y}$ & $\mathrm{N}$ & $\mathrm{N}$ & $\mathrm{Y}$ & $\mathrm{N}$ & $\mathrm{N}$ & $\mathrm{N}$ & **(Hildebrand et al. 2013) & $\mathrm{Y}$ & $\mathrm{Y}$ & $\mathrm{Y}$ & $\mathrm{N}$ & $\mathrm{Y}$ & $\mathrm{Y}$ & $\mathrm{N}$ & $\mathrm{Y}$ & $\mathrm{N}$ \\
\hline *(Song and Kim 2006) & $\mathrm{Y}$ & $\mathrm{Y}$ & $\mathrm{N}$ & $\mathrm{Y}$ & $\mathrm{Y}$ & $\mathrm{Y}$ & $\mathrm{N}$ & $\mathrm{Y}$ & $\mathrm{N}$ & (Wang et al. 2013) & $\mathrm{Y}$ & $\mathrm{Y}$ & $\mathrm{Y}$ & $\mathrm{Y}$ & $\mathrm{Y}$ & $\mathrm{Y}$ & $\mathrm{Y}$ & $\mathrm{Y}$ & $\mathrm{N}$ \\
\hline (Li et al. 2006) & $\mathrm{Y}$ & $\mathrm{N}$ & $\mathrm{Y}$ & $\mathrm{N}$ & $\mathrm{N}$ & $\mathrm{Y}$ & $\mathrm{N}$ & $\mathrm{N}$ & $\mathrm{N}$ & *(Tsai and Bagozzi 2014) & $\mathrm{Y}$ & $\mathrm{Y}$ & $\mathrm{Y}$ & $\mathrm{N}$ & $\mathrm{Y}$ & $\mathrm{Y}$ & $\mathrm{N}$ & $\mathrm{Y}$ & $\mathrm{Y}$ \\
\hline *(Bagozzi et al. 2006) & $\mathrm{Y}$ & $\mathrm{Y}$ & $\mathrm{Y}$ & $\mathrm{N}$ & $\mathrm{N}$ & $\mathrm{Y}$ & $\mathrm{N}$ & $\mathrm{Y}$ & $\mathrm{N}$ & *(Kuan et al. 2014) & $\mathrm{Y}$ & $\mathrm{Y}$ & $\mathrm{N}$ & $\mathrm{Y}$ & $\mathrm{Y}$ & $\mathrm{Y}$ & $\mathrm{N}$ & $\mathrm{Y}$ & $\mathrm{Y}$ \\
\hline *(Bagozzi et al. 2007) & $\mathrm{Y}$ & $\mathrm{Y}$ & $\mathrm{Y}$ & $\mathrm{N}$ & $\mathrm{N}$ & $\mathrm{Y}$ & $\mathrm{Y}$ & $\mathrm{Y}$ & $\mathrm{N}$ & $* *($ Zhang et al. 2014$)$ & $\mathrm{N}$ & $\mathrm{N}$ & $\mathrm{N}$ & $\mathrm{Y}$ & $\mathrm{N}$ & $\mathrm{N}$ & $\mathrm{Y}$ & $\mathrm{N}$ & $\mathrm{Y}$ \\
\hline *(Miller and Brunner 2008) & $\mathrm{Y}$ & $\mathrm{N}$ & $\mathrm{N}$ & $\mathrm{Y}$ & $\mathrm{N}$ & $\mathrm{Y}$ & $\mathrm{Y}$ & $\mathrm{Y}$ & $\mathrm{Y}$ & (Godinho de Matos et al. 2014) & $\mathrm{N}$ & $\mathrm{Y}$ & $\mathrm{N}$ & $\mathrm{Y}$ & $\mathrm{N}$ & $\mathrm{Y}$ & $\mathrm{N}$ & $\mathrm{N}$ & $\mathrm{Y}$ \\
\hline **(Walther et al. 2008) & $\mathrm{N}$ & $\mathrm{N}$ & $\mathrm{N}$ & $\mathrm{Y}$ & $\mathrm{N}$ & $\mathrm{N}$ & $\mathrm{Y}$ & $\mathrm{N}$ & $\mathrm{N}$ & $* *$ (Hu et al. 2015$)$ & $\mathrm{N}$ & $\mathrm{N}$ & $\mathrm{N}$ & $\mathrm{N}$ & $\mathrm{N}$ & $\mathrm{N}$ & $\mathrm{N}$ & $\mathrm{N}$ & $\mathrm{N}$ \\
\hline (Eckhardt et al. 2009) & $\mathrm{Y}$ & $\mathrm{N}$ & $\mathrm{N}$ & $\mathrm{Y}$ & $\mathrm{Y}$ & $\mathrm{Y}$ & $\mathrm{N}$ & $\mathrm{Y}$ & $\mathrm{N}$ & **(Wang et al. 2015) & $\mathrm{N}$ & $\mathrm{N}$ & $\mathrm{N}$ & $\mathrm{N}$ & $\mathrm{N}$ & $\mathrm{N}$ & $\mathrm{N}$ & $\mathrm{N}$ & $\mathrm{N}$ \\
\hline (Yang et al. 2009) & $\mathrm{Y}$ & $\mathrm{Y}$ & $\mathrm{Y}$ & $\mathrm{N}$ & $\mathrm{Y}$ & $\mathrm{Y}$ & $\mathrm{Y}$ & $\mathrm{Y}$ & $\mathrm{Y}$ & **(Matook et al. 2015) & $\mathrm{Y}$ & $\mathrm{Y}$ & $\mathrm{N}$ & $\mathrm{Y}$ & $\mathrm{N}$ & $\mathrm{Y}$ & $\mathrm{N}$ & $\mathrm{Y}$ & $\mathrm{N}$ \\
\hline **(Mangold and Faulds 2009) & $\mathrm{N}$ & $\mathrm{N}$ & $\mathrm{N}$ & $\mathrm{N}$ & $\mathrm{Y}$ & $\mathrm{N}$ & $\mathrm{N}$ & $\mathrm{N}$ & $\mathrm{N}$ & **(Tussyadiah et al. 2015) & $\mathrm{N}$ & $\mathrm{Y}$ & $\mathrm{Y}$ & $\mathrm{Y}$ & $\mathrm{Y}$ & $\mathrm{Y}$ & $\mathrm{N}$ & $\mathrm{Y}$ & $\mathrm{N}$ \\
\hline$* *$ (Pempek et al. 2009) & $\mathrm{N}$ & $\mathrm{N}$ & $\mathrm{N}$ & $\mathrm{Y}$ & $\mathrm{N}$ & $\mathrm{Y}$ & $\mathrm{N}$ & $\mathrm{N}$ & $\mathrm{N}$ & $* *(O h$ et al. 2017) & $\mathrm{N}$ & $\mathrm{N}$ & $\mathrm{N}$ & $\mathrm{N}$ & $\mathrm{Y}$ & $\mathrm{N}$ & $\mathrm{N}$ & $\mathrm{N}$ & $\mathrm{N}$ \\
\hline (Kulviwat et al. 2009) & $\mathrm{Y}$ & $\mathrm{Y}$ & $\mathrm{Y}$ & $\mathrm{N}$ & $\mathrm{Y}$ & $\mathrm{Y}$ & $\mathrm{N}$ & $\mathrm{Y}$ & $\mathrm{N}$ & $* *($ Sedera et al. 2017$)$ & $\mathrm{Y}$ & $\mathrm{Y}$ & $\mathrm{Y}$ & $\mathrm{Y}$ & $\mathrm{Y}$ & $\mathrm{Y}$ & $\mathrm{N}$ & $\mathrm{Y}$ & $\mathrm{Y}$ \\
\hline$* *$ (Zeng et al. 2009) & $\mathrm{N}$ & $\mathrm{Y}$ & $\mathrm{Y}$ & $\mathrm{N}$ & $\mathrm{N}$ & $\mathrm{Y}$ & $\mathrm{N}$ & $\mathrm{N}$ & $\mathrm{N}$ & **(Thomaz et al. 2017) & $\mathrm{N}$ & $\mathrm{N}$ & $\mathrm{N}$ & $\mathrm{N}$ & $\mathrm{N}$ & $\mathrm{N}$ & $\mathrm{N}$ & $\mathrm{N}$ & $\mathrm{N}$ \\
\hline **(Kaplan and Haenlein 2010) & $\mathrm{Y}$ & $\mathrm{Y}$ & $\mathrm{N}$ & $\mathrm{N}$ & $\mathrm{N}$ & $\mathrm{Y}$ & $\mathrm{Y}$ & $\mathrm{N}$ & $\mathrm{N}$ & **(James et al. 2017) & $\mathrm{N}$ & $\mathrm{N}$ & $\mathrm{N}$ & Y & $\mathrm{N}$ & $\mathrm{N}$ & $\mathrm{N}$ & $\mathrm{N}$ & $\mathrm{N}$ \\
\hline *(Shen et al. 2010) & $\mathrm{Y}$ & $\mathrm{Y}$ & $\mathrm{Y}$ & $\mathrm{Y}$ & $\mathrm{N}$ & $\mathrm{Y}$ & $\mathrm{N}$ & $\mathrm{Y}$ & $\mathrm{N}$ & *(Liao et al. 2017) & $\mathrm{N}$ & $\mathrm{N}$ & $\mathrm{N}$ & $\mathrm{N}$ & $\mathrm{N}$ & $\mathrm{N}$ & $\mathrm{N}$ & $\mathrm{N}$ & $\mathrm{N}$ \\
\hline *(Posey et al. 2010) & $\mathrm{N}$ & $\mathrm{Y}$ & $\mathrm{N}$ & $\mathrm{N}$ & $\mathrm{Y}$ & $\mathrm{Y}$ & $\mathrm{N}$ & $\mathrm{N}$ & $\mathrm{N}$ & ${ }^{* *}$ (Rueda et al. 2017) & $\mathrm{Y}$ & $\mathrm{Y}$ & $\mathrm{N}$ & $\mathrm{Y}$ & $\mathrm{N}$ & $\mathrm{Y}$ & $\mathrm{N}$ & $\mathrm{Y}$ & $\mathrm{N}$ \\
\hline *(Huffaker 2010) & $\mathrm{Y}$ & $\mathrm{N}$ & $\mathrm{N}$ & $\mathrm{N}$ & $\mathrm{Y}$ & $\mathrm{Y}$ & $\mathrm{Y}$ & $\mathrm{Y}$ & $\mathrm{Y}$ & **(Brandt et al. 2017) & $\mathrm{N}$ & $\mathrm{N}$ & $\mathrm{N}$ & $\mathrm{N}$ & $\mathrm{N}$ & $\mathrm{N}$ & $\mathrm{N}$ & $\mathrm{N}$ & $\mathrm{N}$ \\
\hline (Glass and Li 2010) & $\mathrm{Y}$ & $\mathrm{N}$ & $\mathrm{N}$ & $\mathrm{Y}$ & $\mathrm{N}$ & $\mathrm{Y}$ & $\mathrm{N}$ & $\mathrm{Y}$ & $\mathrm{Y}$ & **(Dewan et al. 2017) & $\mathrm{N}$ & $\mathrm{N}$ & $\mathrm{N}$ & $\mathrm{Y}$ & $\mathrm{N}$ & $\mathrm{N}$ & $\mathrm{N}$ & $\mathrm{N}$ & $\mathrm{Y}$ \\
\hline *(Vannoy and Palvia 2010) & $\mathrm{Y}$ & $\mathrm{N}$ & $\mathrm{N}$ & $\mathrm{N}$ & $\mathrm{N}$ & $\mathrm{Y}$ & $\mathrm{N}$ & $\mathrm{Y}$ & $\mathrm{N}$ & (Zhang et al. 2018) & $\mathrm{N}$ & $\mathrm{N}$ & $\mathrm{N}$ & $\mathrm{Y}$ & $\mathrm{N}$ & $\mathrm{N}$ & $\mathrm{N}$ & $\mathrm{N}$ & $Y$ \\
\hline **(Cheung and Lee 2010) & $\mathrm{Y}$ & $\mathrm{Y}$ & $\mathrm{Y}$ & $\mathrm{N}$ & $\mathrm{N}$ & $\mathrm{Y}$ & $\mathrm{N}$ & $\mathrm{Y}$ & $\mathrm{Y}$ & & & & & & & & & & \\
\hline
\end{tabular}

${ }^{6}$ A - Compliance, B - Identification, C - Internalization, D - Peer Influence, E - Informational Influence, F - Normative Influence, G - Immediacy, H - Strength, I - Number of Sources 


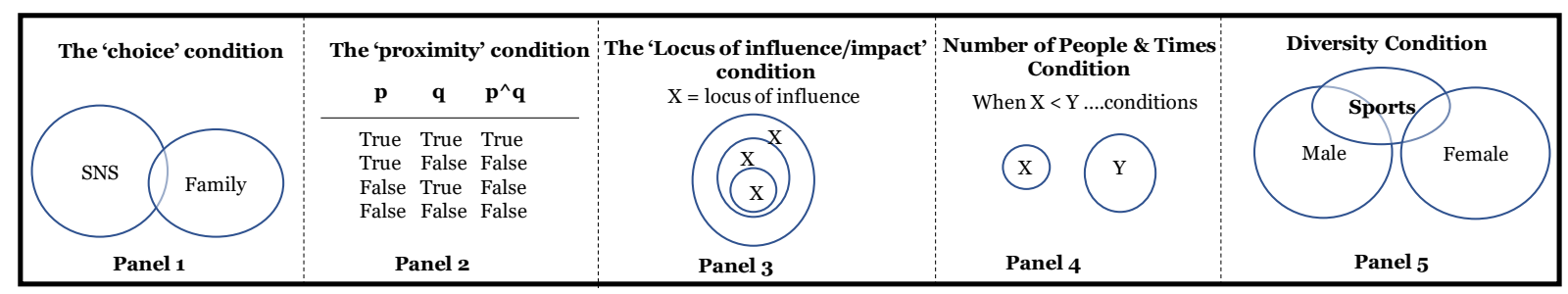

Figure 1. Boundary Conditions for Social Media Research

\subsection{The Choice of the Social Circle}

Figure 1, panel 1 demonstrates the overlap of the family members and SNS. While in the physical world, a person may not have a choice in selecting the people with whom he/she would need to interact (e.g. family members, colleagues), in SNS, a person receives the ability either to add or remove a person from the SNS, and thereby to decide whether or not to interact with another individual in the digital space or not. Moreover, not all the family members will necessarily be in a social network. For instance, Bagozzi and Dholakia (2002) differentiate virtual communities from traditional communities, stating that members of SNS have a voluntary association with the membership. Therein, the individual could quit the network at any given time without participation. Hall and Fagen (1956) argue such boundary conditions as exterior boundary conditions. It is argued that when either a new unit of measurement must be introduced into a theorem, the unit must be designated affirmatively as must be the theorem (Dubin 1969). Hall and Fagen (1956) further state that in such cases when an exterior boundary condition changes the outcome of a proposed model, such variables should be considered as intervening variables (moderation and mediation assumed). In social influence studies, the choice one would exert in determining their own social network, therefore, should be taken into account in future studies. Zhang et al. (2018) investigate the 'direct' vs. 'indirect' peer influence in social media, arguing that "Peer influence can arise from immediate neighbours in the network and from indirect peers who share common neighbours. (p. 1)" Their findings, based on an analysis of call logs, demonstrate significant differences between the direct vs. indirect influences. While such differentiations are visible in the traditional context, deriving such differentiations is nearly impossible in SNS. Therefore, for studies on social influence, the 'choice' condition should be specified, as the influence would only arise from those whom you have selected to be included in your social networks. For example, when such facets like (A) compliance, (B) identification, (C) internalization or (D) peer influence are considered, the choice that the individual has consciously taken must be taken into account. Similarly, when measuring the social impact through constructs like $(\mathrm{G})$ immediacy and $(\mathrm{H})$ strength, these constructs would be impacted by the choice condition.

\subsection{Space and Proximity}

Space and proximity are considered as another suitable boundary condition for SNS studies based on our literature analysis. Herein, we refer to two types of proximities, namely the physical proximity and the digital proximity. While in the social impact theory, Latané argues that physical proximity affected the influence a person makes on another, in SNS settings, we argue that both physical and digital proximity would affect whether or not a person would be influenced by another person. Herein, by digital proximity, we mean the proximity between SNS users in terms of belonging to the same online group or being members of the same page, due to which the SNS users would feel a form of connectedness. Figure 1, panel 2 outlines an example of a truth table for the proximity condition. Therein we argue that both 'p' and 'q' must be understood in social influence studies, where 'p' is the 'digital proximity' and ' $q$ ' is 'physical proximity' that one has to a network or its subjects. Latané and Bourgeois (1996) in their works of the Dynamic Social Impact theory7 highlight that the social influence, at least with respect to memorable interactions, seems to decrease with the square of the distance. However, the same study suggests that with the influence of the technology, the social space between people will be affected and thus the effective distance between people would be reduced. For example, for (C) internalization, a commonly used construct in social influence, there is a high likelihood for internationalization to be optimal if both conditions are true. Similarly, the proximity of influence must be considered in $(\mathrm{G})$ immediacy to recognize the physical and digital distances of the influencer. A study that implicitly discusses the proximity condition is Dewan et al., (2018). They acknowledge the

7Dynamic social impact theory consists of four constructs namely clustering, correlation, consolidation and continuing diversity. Latané and Bourgeois (1996) have utilized these 4 constructs to analyze the user behaviors in electronic groups and thereby to explore the operation of social impact in social space. 
difficulties in assessing the proximity in SNS stating that "identifying proximity influence using observational data is challenging due to homophily, which may influence both the formation of social ties and music consumption decisions" (p. 119).

\subsection{The Locus of Social Influence}

Figure 1, panel 3 denotes the locus of social influence. The boundary condition on the 'the locus of social influence' recognizes that there are multiple 'realms' of networks, not just one layer of social network around an individual. As such, the social influence may arise from any of those realms. However, it is asserted that not all realms would have the same level of social influence. Depending on the nature of the event and the nature of the influencer or the group affiliated, the individual could be receptive to the influencer. For example, '\# Metoo' movement against sexual harassment had active participation from 85 countries (Park 2017). Furthermore, the locus of social influence would have an effect on studies employing the (C) internalization as an aspect of social influence. Given the realms of social networks, internalization may be short-term or long lasting, depending on the locus of control. For instance, Tufekci and Wilson (2012) examining a political protest in Egypt indicate how the political content generated by a few groups such as journalists, and activists, escalated to the level of a real-world protest due to the adoption and the acceptance of the political ideology spread through social media by the general public. Hence, while different messages would be communicated in SNS, facts such as the nature of the influencer, and the nature of the event, would affect different people in SNS to either to be influenced or to not to be influenced based on the relationship a person has with the event and the influencer.

\subsection{The Number of People \& Times}

Figure 1, panel 4 demonstrates the possible effect that the number of people and times has on social influence constructs. Herein, we claim that, the more number of people you are exposed to in an SNS, and the more number of times a particular message is circulated, the higher the tendency of a person to be influenced in the context of SNS. For instance, Facebook indicates individuals having an average of 338 friends (Smith 2017). While the exact number of the average of friends that an individual has may be debatable, it is clear that social networks allow more friends (Mangold and Faulds 2009). As such, when a condition receives more citations due to the number of people in your network citing it, such conditions are likely to have a high influence. The fundamental premise of 'repeated message' (Black 1949) is developed on the premise of the influence of the number and the time premises. As such, constructs like (E) informational influence, and (F) normative influence will be affected by the number of people and times. For instance, Kuan et al. (2014) in their study on online buying behaviours highlight that information on the number of people who have bought a product (informational influence) and the type of people who have 'liked' a product (normative influence) in SNS affect the purchase decisions of the consumers.

\subsection{The Diversity and the Variety of Social Influence}

Figure 1, panel 5 recognizes the diversity and the variety of connections maintained in SNS (Walther et al. 2008). As expressed in panel 5 as an example, we demonstrate how maleness plus sports has a narrower domain than the either one alone. The diversity and the variety of social influence indicate how people would be susceptible for social influence in SNS based on the diversity of the connections a person is exposed to in SNS, and thereby, the variety of social influence a person would receive in SNS. When comparing the diversity and the variety of social influence in traditional vs social networks, Kwahk and Ge (2012, p. 1816) indicate that in the past the social circles had narrower diversity, but with the proliferation of SNS, the social is influence is getting "broader and stronger" making the presence of SNS an important aspect of peoples' lives. As such, the researcher has an obligation to specify which spectrum of social influence is sought.

\section{Conclusion}

Social influence and impact are two vital streams of research that allow us to understand the interactions and the effects of society on an individual (or society). The popular theoretical foundations that investigate social influence are under increasing pressure due to the advent and proliferation of SNS. While much of the works of social influence have added a wealth of knowledge, studies lack a nuanced view of the 'boundary conditions' that are entrenched in SNS. For instance, when utilizing the constructs generated by the social influence theory, the previous studies have identified that not all constructs that generated social influence in the physical world can be applied in the same way to understand the social influence in SNS (Zhou 2011). Identifying this limitation in applying social influence to SNS, this paper 
proposed five boundary conditions and demonstrated how recognizing such boundary conditions upfront can provide better insights. The analysis of the 65 past studies provides us with the confidence to suggest that the boundary conditions are applicable to understand social influence in the contemporary setting of SNS. The overlaps between the constructs of social influence, the percentage of studies using both theorems in a single study, the application of the five boundary conditions to constructs of social influence suggest this wider application. With regard to the limitations of the study, the boundary conditions were derived based only on a literature analysis. The future research can further establish these boundary conditions by conducting empirical tests. However, the identification of the five boundary conditions means that researchers can now develop instruments and procedures to measure these conditions. In terms of knowledge generation, we believe the findings of this study will serve as a theoretical lens for the researchers in the domain of information systems to look at social influence generated by SNS in a new perspective. This would also enable future studies to be more specific in using social influence and make their findings more relevant to the context of SNS. With regard to the practical implications, utilizing the insights we provide in this study by establishing boundary conditions, which are applicable specifically to the context of SNS, the practitioners will be able to develop strategies, which can yield better outcomes with regard to their SNS campaigns. Notably, in terms of social media marketing, the boundary conditions would allow the practitioners to identify the most optimal conditions under which the social influence would be higher, and thus, affect the behaviours of the consumers.

\section{References}

Alarifi, A., Sedera, D., and Recker, J. 2015. "Posters versus Lurkers: Improving Participation in Enterprise Social Networks through Promotional Messages," International Conference on Information Systems (ICIS 2015), The Association for Information Systems (AIS).

Arvidsson, V., and Holmström, J. 2013. "Social Media Strategy: Understanding Social Media, It Strategy, and Organizational Responsiveness in Times of Crisis," Cutter IT Journal (26:12), pp. 18-23.

Bagozzi, R. P., and Dholakia, U. M. 2002. "Intentional Social Action in Virtual Communities," Journal of Interactive Marketing (16:2), pp. 2-21.

Bagozzi, R. P., Dholakia, U. M., and Pearo, L. R. K. 2007. "Antecedents and Consequences of Online Social Interactions," Media Psychology (9:1), pp. 77-114.

Black, J. W. 1949. "The Relation between Message- Type and Vocal Rate and Intensity," Speech Monographs (16:2), pp. 217-220.

Busse, C., Kach, A. P., and Wagner, S. M. 2017. "Boundary Conditions: What They Are, How to Explore Them, Why We Need Them, and When to Consider Them," Organizational Research Methods (20:4), SAGE Publications Sage CA: Los Angeles, CA, pp. 574-609.

Chaffey, D. 2018. "Global Social Media Summary 2018." Retrieved April 06, 2018, from https://www.smartinsights.com/social-media-marketing/social-media-strategy/new-globalsocial-media-research/

Dewan, S., Ho, Y.-J., and Ramaprasad, J. 2017. "Popularity or Proximity: Characterizing the Nature of Social Influence in an Online Music Community," Information Systems Research (28:1), pp. 117-136.

Dholakia, U. M., Bagozzi, R. P., and Pearo, L. K. 2004. "A Social Influence Model of Consumer Participation in Network- and Small-Group-Based Virtual Communities," International Journal of Research in Marketing (21:3), pp. 241-263.

Dubin, R. 1969. Theory Building. New York: Free Press.

Godinho de Matos, M., Ferreira, P., and Krackhardt, D. 2014. "Peer Influence in the Diffusion of the Iphone $3 g$ over a Large Social Network," MIS Quarterly (38:4), pp.1103-1133.

Hall, A. D., and Fagen, R. E. 1956. "Definition of System," General systems (1:1), pp. 18-28.

Huffaker, D. 2010. "Dimensions of Leadership and Social Influence in Online Communities," Human Communication Research (36:4), pp. 593-617.

Kane, G. C., Alavi, M., Labianca, G., and Borgatti, S. P. 2014. "What's Different About Social Media Networks? A Framework and Research Agenda.(Report)," MIS Quarterly (38:1), pp. 274-304.

Kelman, H. C. 1958. "Compliance, Identification, and Internalization Three Processes of Attitude Change," Journal of Conflict Resolution (2:1), pp. 51-60.

Knapton, S. 2016. "Facebook Users Have 155 Friends - but Would Trust Just 4 in a Crisis." https://www.telegraph.co.uk/news/science/science-news/12108412/Facebook-users-have155-friends-but-would-trust-just-four-in-a-crisis.html Retrieved April 06, 2018.

Krippendorff, K. 1980. Content Analysis: An Introduction to Its Methodology. Beverly Hills, CA: Sage. 
Kuan, K. K., Zhong, Y., and Chau, P. Y. 2014. "Informational and Normative Social Influence in GroupBuying: Evidence from Self-Reported and Eeg Data," Journal of Management Information Systems (30:4), pp. 151-178.

Kwahk, K.-Y., and Ge, X. 2012. "The Effects of Social Media on E-Commerce: A Perspective of Social Impact Theory," System Science (HICSS), 2012 45th Hawaii International Conference on: IEEE, pp. 1814-1823.

Latané, B. 1981. "The Psychology of Social Impact," American psychologist (36:4), pp. 343-356.

Latané, B., and Bourgeois, M. J. 1996. "Experimental Evidence for Dynamic Social Impact: The Emergence of Subcultures in Electronic Groups," Journal of Communication (46:4), pp. 35-47.

MacCarthy, R. 2016. "The Average Twitter User Now Has 707 Followers." https://kickfactory.com/blog/average-twitter-followers-updated-2016/_Retrieved April 15, 2018.

Mangold, W. G., and Faulds, D. J. 2009. "Social Media: The New Hybrid Element of the Promotion Mix," Business horizons (52:4), pp. 357-365.

Miller, M. D., and Brunner, C. C. 2008. "Social Impact in Technologically-Mediated Communication: An Examination of Online Influence," Computers in Human Behavior (24:6), pp. 2972-2991.

Nowak, A., Szamrej, J., and Latané, B. 1990. "From Private Attitude to Public Opinion: A Dynamic Theory of Social Impact," Psychological Review (97:3), pp. 362-376.

Oh, C., Roumani, Y., Nwankpa, J. K., and Hu, H.-F. 2017. "Beyond Likes and Tweets: Consumer Engagement Behavior and Movie Box Office in Social Media," Information \& Management (54:1), pp. 25-37.

Palekar, S., Atapattu, M. R., Sedera, D., and Lokuge, S. 2018. "Exploring Spiral of Silence in Digital Social Networking Spaces," International Conference on Information Systems (ICIS 2015): Exploring the Information Frontier: Association for Information Systems (AIS).

Park, A. 2017. "\#Metoo Reaches 85 Countries with $1.7 \mathrm{~m}$ Tweets." https://www.cbsnews.com/news/metoo-reaches-85-countries-with-1-7-million-tweets/

Retrieved April 16, 2018.

"PlumX Metrics - Plum Analytics." (n.d.). https://plumanalytics.com/learn/about-metrics/ Retrieved August 4, 2018.

Sedera, D., Lokuge, S., Atapattu, M., and Gretzel, U. 2017. "Likes-the Key to My Happiness: The Moderating Effect of Social Influence on Travel Experience," Information \& Management (54:6), pp. 825-836.

Sedera, D., Lokuge, S., Salleh, N. A. M., Moghavvemi, S., and Palekar, S. 2016. "Spoilt for Choice: When User-System Relationship Becomes One-to-Many," International Conference on Information Systems (ICIS2016): Association for Information Systems (AIS).

Sinha, J. I., and Fung, T. T. 2018. "The Right Way to Market to Millenials." https://sloanreview.mit.edu/article/the-right-way-to-market-to-millennials/ Retrieved May 01, 2018.

Smith, A. 2014. "What People Like and Dislike About Facebook." http://www.pewresearch.org/facttank/2014/02/03/what-people-like-dislike-about-facebook/ Retrieved April 25, 2018.

Smith, K. 2017. "Marketing: 47 Incredible Facebook Statistics." https://www.brandwatch.com/blog/47-facebook-statistics/ Retrieved April 25, 2018.

Tufekci, Z., and Wilson, C. 2012. "Social Media and the Decision to Participate in Political Protest: Observations from Tahrir Square," Journal of communication (62:2), pp. 363-379.

Vannoy, S. A., and Palvia, P. 2010. "The Social Influence Model of Technology Adoption," Communications of the ACM (53:6), ACM, pp. 149-153.

Vaughan, G., and Hogg, M. A. 2005. Introduction to Social Psychology. Pearson Education Australia.

Walther, J. B., Van Der Heide, B., Kim, S. Y., Westerman, D., and Tong, S. T. 2008. "The Role of Friends' Appearance and Behavior on Evaluations of Individuals on Facebook: Are We Known by the Company We Keep?," Human communication research (34:1), pp. 28-49.

Wang, Y.-Y., Susarla, A., and Sambamurthy, V. 2015. "The Untold Story of Social Media on Offline Sales: The Impact of Facebook in the Us Automobile Industry," International Conference on Information Systems, ICIS 2015 Association for Information Systems.

Zhang, B., Pavlou, P. A., and Krishnan, R. 2018. "On Direct vs. Indirect Peer Influence in Large Social Networks," Information Systems Research, INFORMS (29:2), pp. 292-314.

Zhou, T. 2011. "Understanding Online Community User Participation: A Social Influence Perspective," Internet research (21:1), pp. 67-81. 


\section{Acknowledgements}

This research was supported by the Australian Government Research Training Program Scholarship and Monash University.

Copyright: (C) 2018 Chandrasekara and Sedera. This is an open-access article distributed under the terms of the Creative Commons Attribution-NonCommercial 3.0 Australia License, which permits noncommercial use, distribution, and reproduction in any medium, provided the original author and ACIS are credited. 